\title{
An optimized method for mass rearing the tiger-fly, Coenosia attenuata (Diptera: Muscidae)
}

\author{
Joana MARTINS ${ }^{1,2}$, Célia MATEUS ${ }^{1,3, *}$, Ana C. RAMOS ${ }^{1}$ and Elisabete FIGUEIREDO ${ }^{2,3}$ \\ ${ }^{1}$ Instituto Nacional de Investigação Agrária e Veterinária, Av. da República, Quinta do Marquês, 2784-505 Oeiras, Portugal; \\ e-mails: celia.mateus@iniav.pt; cristina.ramos@iniav.pt \\ ${ }^{2}$ Instituto Superior de Agronomia, Universidade de Lisboa, Tapada da Ajuda, 1349-017 Lisboa, Portugal; \\ e-mails: joanam@isa.ulisboa.pt; elisalacerda@isa.ulisboa.pt \\ ${ }^{3}$ LEAF, ISA, Tapada da Ajuda, 1349-017 Lisboa, Portugal
}

Key words. Diptera, Muscidae, Coenosia, tiger-fly, mass rearing, biological control, predator, prey, Sciaridae, Bradysia

\begin{abstract}
The tiger-fly Coenosia attenuata Stein (Diptera: Muscidae) is a predator that is currently thought to be a useful biological control agent in greenhouses, especially in the Mediterranean region. Here, we present a method for rearing this predator in the laboratory by feeding it on fungus gnats (fed on Pleurotus ostreatus fungus) and drosophilids (Diptera). Over the past two years, this method has been continuously used to successfully produce predators for bioecological studies in the laboratory. Rearing cages with one, five or 10 male-female pairs, either of laboratory or field origin, were compared using females that were either unmated and recently emerged, or mated and about 20 days old (post-emergence). We evaluated the following parameters: number of rearing cages in which adults emerged, number and sex ratio of emerged adults, period from the introduction of parental pairs into cages and the emergence of the first offspring adults, and the period over which emergence occurred in the cages. Based on our results and in order to minimize the space needed for the colony, cages should be stocked with ca. 10 parental pairs, either of field or laboratory origin, with at least some mated females about 20 days post emergence. We also found that the predator's rearing substrate in the cages is improved if coconut fibre is mixed with the soil. These findings will improve the efficiency of $C$. attenuata rearing, an important step if it is to be used as a biological control agent.
\end{abstract}

\section{INTRODUCTION}

Greenhouse crops in the Mediterranean region are affected by several pests. The tiger-fly, Coenosia attenuata Stein, 1903 (Diptera: Muscidae), is a useful biological control agent of many of these pests, as both the larvae and adults are predators (Moreschi \& Colombo, 1999; Sensenbach, 2004). It is also one of the only known species to feed on adult fungus gnats, shore flies, whiteflies and leafminers (Kühne, 1998, 2000). In addition, C. attenuata possesses other traits that favour its use as a biological control agent in greenhouses, such as a tolerance of high temperatures (Gilioli et al., 2005) and the fact that it kills more prey than it can consume (Martinez \& Cocquempot, 2000). Coenosia attenuata is distributed worldwide (Hennig, 1964; Pohl et al., 2011) and was first detected in Portugal in 2001, in the Oeste region (Prieto et al., 2005; Martins et al., 2012).

Laboratory methods for rearing $C$. attenuata have been under development for several years. Kühne et al. (1994) describe a "three-step rearing method" that involves rearing species of Bradysia Winnertz, 1867 (Diptera: Sciaridae) on a substrate of wood-fibre mixed with species of Fusarium Link, 1809 (Ascomycota: Hypocreales: Nectriaceae), which then serves as an oviposition substrate for $C$. attenuata. Fungus gnat larvae and adults were, respectively, used as prey for $C$. attenuata larvae and adults. In vitro rearing based on artificial laboratory diets has not been successful (Valentini, 2009).

Attempts to improve the rearing of species of Coenosia Meigen, 1826 have been made by other authors. These include (1) using fungus and fungus gnat species as the predator's food source (Moreschi \& Colombo, 1999; Sensenbach et al., 2005; Valentini, 2009; Ugine et al., 2010); (2) adjusting the type and relative proportions of the constituents of the rearing diet (coconut coir, soil, pieces of bark, mulch, oat flakes, pinto beans, yeast extracts) (Moreschi \& Colombo, 1999; Sensenbach et al., 2005; Valentini, 2009; Ugine et al., 2010); (3) feeding the larvae of Coenosia spp. on other organisms such as larvae of Holoplagia (= Scatopse) transversalis (Loew, 1836) (Diptera: Scatopsidae), pre-killed $1^{\text {st }}$ instar Ostrinia nubilalis (Hübner, 1796) (Lepidoptera: Pyralidae) and pieces of the earthworm Eisenia fetida (Savigny, 1826) (Annelida: Opisthopora: Lumbricidae) (Moreschi \& Süss, 1998; Kühne, 2000); (4) the addition of Drosophila (Sophophora) melanogaster Meigen, 1830 adults as complementary prey for the adults of the predator (Moreschi \& Süss, 1998; Moreschi \& Colombo, 1999); and (5) the use of a complementary sugar source (diluted or undiluted honey) (Sensenbach et al., 2005; Valentini, 2009).

Several problems with these methods are reported, including economically prohibitive costs, time consumption,

\footnotetext{
* Corresponding author.
} 
quantity and periodicity of the individuals produced and contamination by other organisms (Kühne, 2000; Valentini, 2009; D. Lupi, pers. comm.).

The objective of this study was to improve the method of rearing $C$. attenuata, so that in the future this species could be efficiently produced for biological control programmes, namely by using open rearing units commonly used in other commercial production systems. The rearing method presented here results from a gradual adaptation of the rearing methods described in literature, which can be followed in Martins (2011). This modified method has been used successfully for the past two years to produce predators for laboratory trials. To further improve this rearing process, experiments were conducted to determine the effect of (1) the number, origin and age of tiger-fly parental pairs, (2) the number of fungus gnat larvae present in the substrate, and (3) the rearing substrate on the occurrence (or not) of emergence in the rearing cages, on the number of offspring per pair, on the sex ratio of the offspring, on the period from the introduction of parental pairs into the cages until the first offspring adult emerged and on the period over which adult emergence occurred in the rearing cages.

\section{MATERIAL AND METHODS}

\section{Rearing methodology}

In the rearing units, the larvae of $C$. attenuata fed on the larvae of Bradysia impatiens (Johannsen, 1912) and its adults on the adults of the same species of prey along with adults of $D$. melanogaster. Continuous rearing of these two prey species occurred together with that of the predator. Rearing took place in an acclimatized breeding room kept at a mean daily temperature of 23.0 $\pm 3.2^{\circ} \mathrm{C}$ with a mean daily amplitude of $3.9 \pm 0.2^{\circ} \mathrm{C}$, mean $\mathrm{RH}$ of $65 \pm 10 \%$ and photoperiod of $12 \mathrm{~L}: 12 \mathrm{D}$. According to Moreschi $\&$ Colombo (1999) the optimal rearing conditions for this species are $25^{\circ} \mathrm{C}$ and $70 \% \mathrm{RH}$

\section{Fungus gnats}

Fungus gnats were reared in a substrate of soil with $90 \%$ organic matter ( $80 \%$ black peat, $20 \%$ white peat and $1,100 \mathrm{~g} \mathrm{NPK}$ fertilizer $/ \mathrm{m}^{3}$, previously sterilized at $120^{\circ} \mathrm{C}$ for $30 \mathrm{~min}$ ), mixed with oats that were previously inoculated with Pleurotus ostreatus (Jacquin) Kummer, 1871 (Basidiomycota: Agaricales: Pleurotaceae). To prepare this substrate, $P$. ostreatus cultures were grown in Petri dishes containing PDA (potato dextrose agar) at $24^{\circ} \mathrm{C}$ until this medium is completely colonized by this fungus; the "spawn" or inoculum was prepared using oats that were first washed with running tap water to remove debris, boiled for 20 min, sterilized at $121{ }^{\circ} \mathrm{C}$ for one hour, cooled to room temperature and then inoculated with pure fungal cultures. The oats were then incubated at $24 \pm 2{ }^{\circ} \mathrm{C}$ until completely colonized ("snowball") and the inoculum was then maintained at $3-4^{\circ} \mathrm{C}$ until mixed with soil in a proportion of $3: 1$ (weight of soil : weight of oats). This substrate was placed in open plastic boxes $\left(21 \times 33 \times 9 \mathrm{~cm}^{3}\right)$, occupying about half their volume, inside cages of transparent "étamine" tissue $\left(35 \times 35 \times 58 \mathrm{~cm}^{3}\right)$ and kept moist by frequent spraying with water. Each cage contained two boxes containing this substrate. Fifty to 100 fungus gnat adults were introduced into each cage every $2-3$ days until a total of about 500 fungus gnat adults per cage was reached. After 20-25 days, the first adults of the following generation began to emerge.
In this study, P. ostreatus was used instead of Fusarium sp. (Moreschi \& Colombo, 1999; Kühne, 2000), because its morphology and production is stable and it is easy to cultivate on cereal grains.

\section{Drosophilid flies}

Drosophilids were reared in plastic or glass vials (about 400 $\mathrm{cm}^{3}$ ), closed with mite-proof polyurethane plugs, on an artificial diet $\left(100 \mathrm{~cm}^{3}\right.$ per vial) composed of $10.0 \mathrm{~g}$ yeast extract, $35.0 \mathrm{~g}$ maize flour, $5.0 \mathrm{~g}$ agar, $37.5 \mathrm{~g}$ sugar, $22.5 \mathrm{~g}$ malt extract, $550.0 \mathrm{ml}$ of boiling water and $12.5 \mathrm{ml}$ of Nipagin ${ }^{\circledR}$ (methyl hydroxybenzoate). The diet was sterilized at $120^{\circ} \mathrm{C}$ for $30 \mathrm{~min}$ before adding the last ingredient. Adults were introduced into the vials and the adults of the following generation started to emerge after about 12 days.

Tiger-fly

The substrate containing fungus gnat larvae (described above) was removed from the "étamine" tissue cages one week after the emergence of the first adults, and placed in open plastic boxes $\left(25.0 \times 14.0 \times 3.5 \mathrm{~cm}^{3}\right)$, where it occupied almost the total volume of the box $\left(\approx 1085 \mathrm{~cm}^{3}\right)$. These boxes were placed individually into new "étamine" tissue cages with about ten male-female pairs of tiger-flies. These individuals originated from laboratory colonies that were supplemented about every four generations with adults captured in the field (in this case in greenhouses in the Oeste region, which is located near the coast northwest of Lisbon). For "refreshing purposes" one or two of these field-caught adults, depending on availability, were introduced into the rearing cages. Each cage had a metal structure inside, which consisted of thick wire bent into the shape of a parallelepiped, which was used as a perch by adult predators. To complement the predators' diet, 10-15 adult drosophilids per predator were introduced daily into each cage. Kühne (2000) states that each adult predator needs either 1.5 adults of D. melanogaster or 6.9 adults of Bradysia paupera Tuomikoski, 1960 (synonym to B. impatiens, according to Mohrig et al., 2012) per day. The higher number of drosophilids used was intended to minimize the incidence of cannibalism by adult predators reported by Téllez \& Tapia (2007) and Ugine et al. (2010), but not by the authors in either of the rearing units or in the field (Mateus, 2012). While rearing drosophilids is quick, easy and not particularly expensive, they were used primarily as a complement to the fungus gnat diet because $C$. attenuata fertility is lower when fed drosophilids compared to fungus gnats (Kühne et al., 1997). For 20 days, females of the predator were allowed to lay their eggs in the substrate, which was regularly sprayed with tap water to maintain a water content at about $70 \%$. After this period, the substrates were placed inside new "étamine" tissue cages, without tiger-fly adults or humidification, to await the emergence of adults. Maintaining substrate moisture is crucial for rearing success, as is not watering just prior to adult emergence. Ugine et al. (2010) suggest that the high pupal mortality they recorded for $C$. attenuata was due to the substrate being saturated with water, which is supported by the results of our preliminary observations (Martins, 2011). A 20 day period was chosen because Kühne et al. (1997) report that females of C. attenuata lay $92 \%$ of their eggs in the first three weeks, when reared at $25^{\circ} \mathrm{C}$. Of the adults that emerged, some were used in predation and behavioural assays and the remainder for rearing.

\section{Experiments}

Exp. \#1. Effect of the number, origin and age of tiger-fly parental pairs

"Étamine" tissue cages containing an open plastic box of humidified substrate infested with fungus gnat larvae, the same as 
described above for rearing the colonies, were used in this experiment. One, five, or 10 pairs of C. attenuata were introduced into each cage, with a total of 40,29 and 17 cages for these treatments, respectively. Flies used were collected from greenhouses or laboratory reared (generation number not controlled), as given in Table 1. Two treatments of laboratory reared females were used: "unmated recently emerged" and "mated and older" (being about 20 days old and had already laid eggs in the laboratory rearing units) (Table 1). Males were all "unmated and recently emerged". In addition, 10 to 15 drosophilids per predator adult were introduced per day. Cages were checked daily and the following recorded: occurrence (or not) of emergence, the number of adults that emerged per pair, the sex ratio (number of females/ total), the period from the introduction of parental pairs into the cages until the first adult offspring emerged (which included parental pre-mating, mating, pre-oviposition, oviposition and development periods; MODP) and the period over which emergence occurred (EP). Cages used in this analysis were those in which adults emerged (11, 29 and 17 cages with one, five and 10 pairs/ cage, respectively). Data collection was terminated one week after the last adult emerged.

Adult longevity of 32 female and 30 male offspring was recorded in the five pairs/cage treatment based on monitoring the cages daily. In addition, the proportion of females that survived (number of alive females/ total females) was calculated for the cages with laboratory reared pairs (recently emerged or 20 days old) at the end of the 20 day period when the parental pairs were removed from the rearing cages.

Exp. \#2. Effect of the number of fungus gnat larvae in the substrate

Before adding pairs of adult tiger-flies to the cages, the number of fungus gnat larvae in the substrate in each box was counted. In each box, the number of larvae was determined in $20 \mathrm{~g}$ of substrate, from a pool of five samples, each sample being $4 \mathrm{~g}$ of substrate collected vertically from top to the bottom of the substrate at five randomly selected positions in each box. The samples were searched under a stereoscope microscope and numbers of fungus gnat larvae in the total substrate calculated based on the weight of each box. Further analyses were carried out for the cages where emergence occurred, taking into consideration the number of adult tiger-flies that emerged per pair, and the MODP and EP parameters.

\section{Exp. \#3. Effect of the rearing substrate}

The effects of three substrates were determined in this experiment: soil (S), a mixture of soil and coconut fibre (M), and layers of soil and coconut fibre (CS).

To prepare the substrates used in the different treatments, soil rich in organic matter as well as blocks of compressed coconut fibre were sterilized at $120^{\circ} \mathrm{C}$ for $30 \mathrm{~min}$. The soil used in these treatments was mixed with oats inoculated with $P$. ostreatus at a ratio of $3: 1$ (soil : oats). The coconut fibre was also mixed with oats inoculated with the fungus, also at a $3: 1$ ratio. Each of these mixtures was placed in open plastic boxes $\left(21 \times 33 \times 9 \mathrm{~cm}^{3}\right)$ and then placed individually inside a transparent tissue cage.

About 500 fungus gnat adults were introduced per cage (see the rearing procedure for fungus gnats described above). One week after the emergence of the first fungus gnat adults, three types of substrate were prepared using the infested soil and coconut fibre, previously mixed with fungus-inoculated oats.

The three types of substrates (S, M, CS) differed in the presence/absence and location of the coconut fibre and were as follows: soil without coconut fibre (S), which corresponds to the substrate used for the stock culture and here used as a control; a mixture $(3: 2)$ of soil and coconut fibre $(\mathrm{M})$; and finally, two vertical layers of shredded coconut fibre enclosing a vertical layer of soil (CS). The addition of coconut fibre was intended to create drier conditions for pupae. These substrates were put in open plastic boxes $\left(25.0 \times 14.0 \times 3.5 \mathrm{~cm}^{3}\right)$, occupying almost the total volume $\left(\approx 1085 \mathrm{~cm}^{3}\right)$, and each box was placed inside a tissue cage with five pairs of $C$. attenuata obtained from the laboratory stock culture. Due to the limited amount of space in the rearing room and the fact that the temperature inside the room could not be fully controlled, a randomized complete block design was used to overcome the effect of this variation. Twelve complete blocks were constituted, one block at a time.

Substrates were regularly sprayed with tap water during the 20 days; for substrate CS, just the soil portion was humidified. At the end of the 20 days, each substrate box was placed in a new cage without $C$. attenuata adults and without further watering.

The number of fungus gnat larvae was determined as indicated above, except for the CS treatment where five $4 \mathrm{~g}$ samples were taken from the soil and the coconut fibre, and the total number determined using the total weight of each of the component parts of this substrate. The number and sex of adult predators that emerged and the MODP and EP parameters indicated above were also determined. Data collection ended one week after no further emergence of predators was recorded.

All experiments were conducted in an acclimatized breeding room, at the same temperature, $\mathrm{RH}$ and photoperiod, as indicated above for the routine rearing units.

\section{Statistical analysis}

The effect of tiger-fly origin on the number of cages from which progeny emerged was analysed using contingency tables. Parametric tests were used whenever parametric analysis assumptions were fulfilled. The t-test for independent samples was used for evaluating longevity. A one-way ANOVA was used to evaluate the effect of a female's age on the number and sex-ratio of her offspring, and also on EP. Two-way ANOVA was used to evaluate the effect of the number of pairs/cage and their origin on the number and sex ratio of the offspring, and also to evaluate the effect of the rearing substrate on the number and sex ratio of the offspring, MODP, EP and the number of fungus gnat larvae in the substrate. Linear and polynomial regressions were used to determine the relationship between the number of tiger-flies that emerged and the number of fungus gnat larvae in the substrate. Data were transformed to correct for non-normal distributions and/or homoscedasticity in the following cases: effect of the number of pairs/cage and their origin on sex ratio (arcsine $V_{x}$ ), evaluation of longevity $[\sqrt{ }(x+1)]$ and effect of rearing substrate on the number of adult progeny $\left(\log _{10} \mathrm{x}\right)$. The non-parametric tests used were the Kruskal-Wallis test (to determine the effect of female age on MODP, effect of the origin of the pairs on MODP and EP, and the proportion of females that survived in the different female age treatments), and the Spearman correlation, used to determine the effect of the number of fungus gnat larvae on MODP and EP.

Only the results for cages in which adult progeny emerged were analysed statistically. When evaluating the effect of female age, only data from the treatment with 10 pairs were used.

In terms of the effect of the number of pairs per cage and the substrate, the increase in the number of individuals in each generation was calculated for each cage by dividing the number of the adult offspring recorded by the number of parent adults introduced into the cage (Moreschi \& Colombo, 1999).

Data are presented as means \pm standard errors of the mean. The significance level was $\alpha=0.05$. All the statistical tests were done 
TABle 1. The numbers of pairs of adult Coenosia attenuata tested (number, origin and females' age), number of cages used in the experiments and number of cages in which adult predators emerged.

\begin{tabular}{ccccc}
\hline No. of pairs $(\mathrm{N})$ & Origin & Females' age & No. of cages $(\mathrm{N})$ & No. of cages in which adults emerged $(\mathrm{N})$ \\
\hline 1 & Field & & 19 & 11 \\
& Laboratory & Recently emerged & 21 & 2 \\
& & Old & 0 & 0 \\
5 & Field & & 13 & 13 \\
& Laboratory & Recently emerged & 15 & 15 \\
10 & Field & Old & 1 & 3 \\
& Laboratory & Recently emerged & 6 & 6 \\
\hline
\end{tabular}

using IBM SPSS Statistics 20.0 for Windows (IBM Corporation, Armonk, New York, USA).

\section{RESULTS}

\section{Effect of the number, origin and age of the parental pairs of tiger-flies}

Emergence of offspring adults occurred in all cages with five or 10 parental pairs but in only $32.5 \%$ of the cages with only one parental pair (Table 1). In this last treatment, significant differences were detected in terms of the origin of the parental pairs (contingency table: $\chi^{2}=12.55$, $\mathrm{df}=1$, $P<0.001 ; \mathrm{n}=42$ ): emergence occurred in $57.9 \%$ of cages initiated with field collected individuals but only $9.5 \%$ of cages initiated with laboratory reared individuals.

The number of adults that emerged per parental pair ranged from 1.8 to 9.0 (= per pair progeny production, or the number of adult offspring that emerged in each cage divided by the number of parental pairs). For per pair progeny production, no significant differences were detected between the different numbers of pairs per cage or between the two parental origins (field vs. laboratory) (Table 2; two-way ANOVA, respectively: $\mathrm{F}=0.270, \mathrm{df}=2,51$, $P=0.764 ; \mathrm{F}=1.272$, df $=1,51, P=0.265)$. However, significant differences in the per pair progeny production were recorded between the two treatments using females of different ages (Table 2; one-way ANOVA: $\mathrm{F}=15.449$, $\mathrm{df}=1,12, P=0.002)$. The increase in the number of in- dividuals per generation was $2.80 \pm 0.28,2.34 \pm 0.16$ and $2.10 \pm 0.13$ for treatments with one, five or 10 pairs per cage, respectively.

In terms of tiger-fly offspring sex ratio, no significant differences were detected either between the treatments with different numbers of parental pairs per cage or flies of two origins (field vs. laboratory) (Table 2; two-way ANOVA, respectively: $\mathrm{F}=2.409$, $\mathrm{df}=2,46, P=0.101 ; \mathrm{F}=0.009$, df $=1,46, P=0.924)$. In addition, no significant differences in progeny sex ratio were recorded due to female age (Table 2; one-way ANOVA: $\mathrm{F}=0.456, \mathrm{df}=1,12, P=0.512$ ).

For the tiger-fly mating, pre-oviposition, oviposition and development period (MODP), no significant differences were detected (Kruskal-Wallis test: $\chi^{2}=2.767$, df $=1, P=$ $0.096, \mathrm{n}=57$ ) between the treatments with the two parental origins (field vs. laboratory). However, significant differences were detected between the treatments with females of different ages (Table 2; Kruskal-Wallis test: $\chi^{2}=10.680$, $\mathrm{df}=1, P=0.001, \mathrm{n}=14)$.

Finally, for the duration of the period over which the tiger-fly emerged (EP), no significant differences were found between treatments with parental pairs of different origins (Table 2; Kruskal-Wallis test: $\chi^{2}=2.943$, df $=1, P$ $=0.086, \mathrm{n}=57$ ) or females of different ages (Table 2 ; oneway ANOVA: $\mathrm{F}=0.129, \mathrm{df}=1,12, P=0.725)$.

Longevity of female progeny was significantly longer than that of male progeny (female mean longevity: $39.2 \pm$

TABLE 2. Number and sex ratio of the adults of Coenosia attenuata (mean $\pm \mathrm{SE}$ ) that emerged in the cages and durations (mean $\pm \mathrm{SE}$ ) of two biological periods (MODP ${ }^{1}$ and $\mathrm{EP}^{1}$ ) of the offspring produced by the different numbers of parental pairs.

\begin{tabular}{|c|c|c|c|c|}
\hline & Offspring / pair (number) ${ }^{2}$ & Offspring sex ratio ${ }^{2}$ & MODP (days) ${ }^{2}$ & $\mathrm{EP}(\text { days })^{2}$ \\
\hline \multicolumn{5}{|c|}{ Number of parental pairs } \\
\hline 1 & $5.4 \pm 0.6 \mathrm{a}$ & $0.54 \pm 0.07 \mathrm{a}$ & & \\
\hline 5 & $4.7 \pm 0.3 \mathrm{a}$ & $0.61 \pm 0.01 \mathrm{a}$ & & \\
\hline 10 & $4.2 \pm 0.3 \mathrm{a}$ & $0.59 \pm 0.01 \mathrm{a}$ & & \\
\hline \multicolumn{5}{|l|}{ Origin of parental pairs } \\
\hline field & $4.9 \pm 0.4 \mathrm{a}$ & $0.56 \pm 0.03 \mathrm{a}$ & $32.4 \pm 1.1 \mathrm{a}$ & $11.1 \pm 0.7 \mathrm{a}$ \\
\hline laboratory & $4.5 \pm 0.2 \mathrm{a}$ & $0.62 \pm 0.02 \mathrm{a}$ & $34.1 \pm 0.9 \mathrm{a}$ & $12.9 \pm 0.7 \mathrm{a}$ \\
\hline \multicolumn{5}{|l|}{ Mother's age ${ }^{3}$} \\
\hline recently emerged & $3.2 \pm 0.3 \mathrm{a}$ & $0.58 \pm 0.03 \mathrm{a}$ & $41.7 \pm 1.4 \mathrm{a}$ & $12.5 \pm 0.9 \mathrm{a}$ \\
\hline about 20 days age & $4.9 \pm 0.3 \mathrm{~b}$ & $0.59 \pm 0.01 \mathrm{a}$ & $36.2 \pm 1.2 \mathrm{~b}$ & $13.0 \pm 1.0 \mathrm{a}$ \\
\hline
\end{tabular}

${ }^{1} \mathrm{MODP}=$ mating, pre-oviposition, oviposition and development period; $\mathrm{EP}=$ emergence period; ${ }^{2}$ Values for each category followed by the same letter are not significantly different $(\mathrm{P}>0.05) ;{ }^{3}$ Analysis done using data from the treatments with 10 pairs per cage. 
$2.5 \mathrm{~d}$; male: $30.6 \pm 2.4 \mathrm{~d}$; t-test for independent samples: $\mathrm{t}$ $=2.433, \mathrm{df}=60, P=0.018)$. Maximum longevity was 64 days for females and 68 days for males. Significant differences were recorded in the proportions of recently emerged and 20 day-old females that survived $(0.21 \pm 0.05$ and 0.43 \pm 0.06 , respectively; Kruskal-Wallis test: $\chi^{2}=6.722$, df $=$ $1, P=0.010, \mathrm{n}=31)$.

\section{Effect of the number of fungus gnat larvae in the substrate}

The mean number of fungus gnat larvae in the substrate of each box was $997.9 \pm 104.6$, corresponding to about $0.92 \pm 0.10$ larvae $/ \mathrm{cm}^{3}$. There was a correlation between the number of adult tiger-fly offspring and the number of fungus gnat larvae in the substrate. The linear regression model obtained was $\mathrm{y}=10.434+0.015 \mathrm{x}(\mathrm{F}=85.443$, $\left.\mathrm{r}^{2}=0.608, P<0.001, \mathrm{n}=57\right)$. The best goodness of fit was achieved using a cubic polynomial regression model $\left(\mathrm{y}=9.617 * 10^{-9} \mathrm{x}^{3}-3.884 * 10^{-5} \mathrm{x}^{2}+0.057 \mathrm{x}+1.786, \mathrm{~F}=\right.$ $33.684, \mathrm{r}^{2}=0.656, P<0.001, \mathrm{n}=57$ ) (Fig. 1).

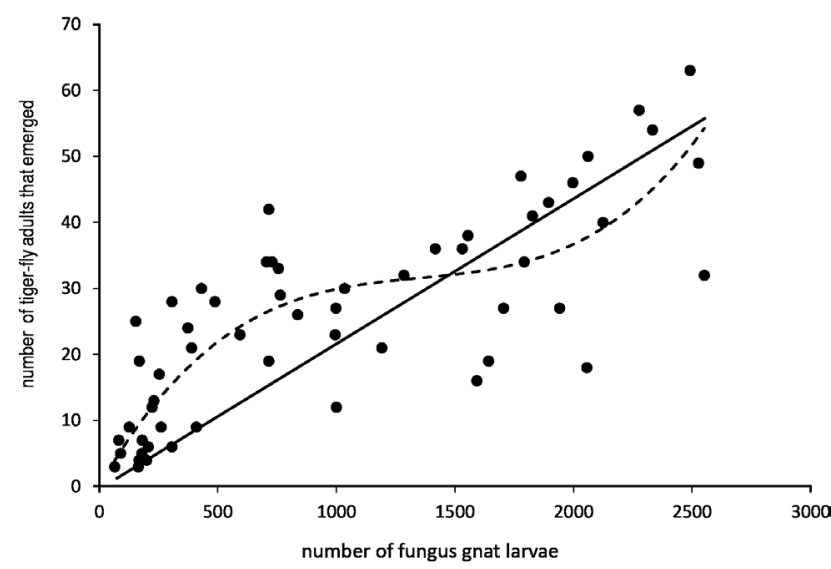

Fig. 1. The relationship between the number of adults of Coenosia attenuata that emerged and the number of fungus gnat larvae in the substrate. (Linear regression model: $y=10.434+$ $0.015 \mathrm{x}, \mathrm{r}^{2}=0.608$; polynomial regression model: $\mathrm{y}=9.617 *$ $\left.10^{-9} \mathrm{x}^{3}-3.884 * 10^{-5} \mathrm{x}^{2}+0.057 \mathrm{x}+1.786, \mathrm{r}^{2}=0.656\right)$.

The variations in both the biological periods studied, MODP and EP, were positively weakly / moderately, but significantly, correlated with the number of fungus gnat larvae in the substrate (Spearman correlation with MODP: $\rho=0.279, P=0.036, \mathrm{n}=57$; Spearman correlation with EP: $\rho=0.401, P=0.002, \mathrm{n}=57)$.

\section{Effect of the rearing substrate}

Of the three substrates tested, a significantly higher number of progeny emerged from substrate $\mathrm{M}$ (mixture of soil and coconut fibre) than S (soil) or CS (two vertical layers of coconut fibre enclosing a vertical layer of soil) (Table 3; two-way ANOVA: $\mathrm{F}=13.950$, df $=2,22, P<0.001$ ) and associated with this, was a correspondingly greater increase in the number of individuals in each generation $(4.06 \pm 0.70$ compared to $3.02 \pm 0.42$, and $2.70 \pm 0.38$, respectively), and significantly higher sex ratio in relation to CS (Table 3; two-way ANOVA: $\mathrm{F}=3.918, \mathrm{df}=2,19, P$ $=0.038)$. No significant differences were recorded between substrates in terms of MODP (Table 3; two-way ANOVA: $\mathrm{F}=1.000, \mathrm{df}=2,22, P=0.384$ ) or EP (Table 3; two-way ANOVA: $\mathrm{F}=0.205, \mathrm{df}=2,22, P=0.816)$. Substrate $\mathrm{S}$ produced the highest number of fungus gnat larvae (2.06 \pm 0.12 per $\mathrm{cm}^{3}$ ) and significantly more than the CS substrate (Table 3; two-way ANOVA: $\mathrm{F}=11.921$, df $=2,22, P<$ $0.001)$.

\section{DISCUSSION AND CONCLUSIONS}

The number of adult predators that emerged in the following generation using the method presented here was low compared to what is considered common for insects. Nevertheless, the increase in the number of individuals in each generation tended to be higher than that recorded by Moreschi \& Colombo (1999). The number of offspring obtained was sufficient for the purposes of this routine laboratory rearing, since several trials on the bioecology of this predator were conducted recently using adults produced by adjusting the number of rearing units.

The routine rearing cages used in this study held about ten pairs per cage. It was hypothesized that under such conditions, the territorial behaviour of $C$. attenuata, which was recorded in the field (Mateus, 2012), could affect the outcome. In addition, competition between tiger-fly larvae for resources could negatively affect their development and consequently the number of adults that emerge in the following generation. A lower number of pairs per cage was used in this study to determine if this is the case. The treatment with one pair per cage gave poor results, with only $32.5 \%$ of the cages producing adults. With just one male in a cage, there may be a high risk of failure in the mating or fertilization processes, as Morris \& Cloutier (1987) report that Coenosia tigrina (Fabricius, 1775) females occasionally refuse males that attempt to mate with them. In addition, $100 \%$ of the cages with 5 and 10 pairs produced

TABLE 3. Number and sex ratio of the adults of Coenosia attenuata that emerged, number of fungus gnat larvae (mean $\pm \mathrm{SE})$ and duration (mean $\pm \mathrm{SE}$ ) of two biological periods ${ }^{1}$ (MODP and EP) recorded for the three substrate treatments ${ }^{2}$ (S, M and CS) (Five females and five males were used in each replicate, with 12 replications).

\begin{tabular}{lccccc}
\hline Substrate & Offspring (number) $^{3}$ & Offspring sex ratio $^{3}$ & ${\text { MODP }(\text { days })^{3}}$ & EP $(\text { days })^{3}$ & Number of fungus gnat larvae $^{3}$ \\
\hline $\mathrm{S}$ & $30.2 \pm 4.2 \mathrm{~b}$ & $0.64 \pm 0.01 \mathrm{ab}$ & $39.5 \pm 2.4 \mathrm{a}$ & $15.4 \pm 1.0 \mathrm{a}$ & $2240.5 \pm 136.7 \mathrm{a}$ \\
$\mathrm{M}$ & $40.6 \pm 7.0 \mathrm{a}$ & $0.67 \pm 0.02 \mathrm{a}$ & $39.2 \pm 2.3 \mathrm{a}$ & $15.9 \pm 1.2 \mathrm{a}$ & $1823.8 \pm 302.8 \mathrm{ab}$ \\
$\mathrm{CS}$ & $27.0 \pm 3.8 \mathrm{~b}$ & $0.60 \pm 0.02 \mathrm{~b}$ & $39.5 \pm 2.3 \mathrm{a}$ & $15.7 \pm 1.1 \mathrm{a}$ & $1117.6 \pm 79.5 \mathrm{~b}$ \\
\hline
\end{tabular}

${ }^{1} \mathrm{MODP}=$ mating, oviposition and development period; $\mathrm{EP}=$ emergence period; ${ }^{2} \mathrm{~S}=$ soil; $\mathrm{M}=$ mixture of soil and coconut fibre; $\mathrm{CS}$ $=$ vertical layers of soil + coconut fibre; ${ }^{3}$ Values for each category followed by the same letter are not significantly different $(P>0.05)$. 
adults, which indicate numbers of pairs of this order are more effective for laboratory rearing. Ten pairs per cage, compared to the other densities tested, reduced the number of cages and space required for the stock culture.

When analysing the number of adult offspring per parental pair that emerged in the cages with one, five and 10 pairs, there was a not significant tendency for a higher number of adult offspring to emerge in the first treatment (one pair). It is possible that if there were more fungus gnat larvae in the substrate (i.e., more food), more offspring per pair would have been produced in the treatments with high numbers of pairs of tiger-flies. Similarly, female larvae, which are bigger than male larvae at the end of their larval development, probably need more food than male larvae, and so the offspring sex-ratio may also be influenced by the number of fungus gnat larvae in the substrate.

Interestingly, 20 day-old mated females are still very useful for rearing and should be re-used for this purpose. In fact, our experiments with these older females resulted in a significantly higher number of progeny per parental pair and a significantly shorter MODP compared to recently emerged females, probably because they have a greater egg load available for immediate laying.

When establishing rearing cages and re-using individuals it is essential to keep their potential longevity in mind. We found that females lived longer than males, as reported by Kühne et al. (1997). However, these authors record 38 days and 33 days as the maximum female and male longevity, respectively, under laboratory conditions $\left(25^{\circ} \mathrm{C}\right.$ and $50-60 \% \mathrm{RH}$ ) and an estimated longevity of eight weeks under greenhouse conditions. Our predators lived longer, possibly because they had a better food supply and the temperature was lower, since Morris \& Cloutier (1987) report that $C$. tigrina longevity is significantly reduced by an increase in temperature, even from 20 to $25^{\circ} \mathrm{C}$.

No significant advantages were detected between using flies from laboratory or field populations in terms of the four biological parameters measured, or the number of cages from which adult progeny emerged (for treatments with five or 10 pairs per cage). However, it is important to note that our laboratory reared adults were collected from colonies to which field individuals were frequently added to prevent potential declines in fly vigour or fertility as is often recorded in rearing units where this is done less frequently. Some of the laboratory females used in the experiment that determined the effects of colony origin (field vs. laboratory) were re-used and, therefore, probably already fertilized and had already laid some eggs, but the effect of reusing females on the results is believed to be low because this was done in only nine of the 32 replicates.

Soil mixed with coconut fibre (substrate $\mathrm{M}$ ) was the most suitable substrate for rearing tiger-flies because it resulted in a higher number progeny than produced in cages with the other two substrates. Also, the different substrates did not have a significant effect on the two biological periods, MODP and EP. Although no economic analysis was done to determine the additional cost of adding coconut fibre to the rearing substrate, it is likely the additional costs were low. Not mixing soil with coconut fibre, but keeping the fibre separate from the soil in boxes (CS) resulted in a low number of offspring, probably because not all the larvae moved into the layers of coconut fibre to pupate. Although substrate $\mathrm{S}$ was not the best for rearing the predator, probably because of high pupal mortality, it is probably the best substrate for rearing fungus gnats.

The mean number of fungus gnat larvae recorded in the different substrates (maximum $2.06 / \mathrm{cm}^{3}$ ) is considerably lower than the optimal density of 4-5 larvae $/ \mathrm{cm}^{3}$ suggested by Moreschi \& Colombo (1999). Nevertheless, as mentioned before, the increase in the number of adult tiger-flies recorded in each generation (2.70-4.06) tended to be higher than that recorded by these authors (2.03-3.05). This may be attributed to a lower mortality of the larvae and pupae of the tiger-fly or a higher female fertility, probably because of the greater attention given to dampening the substrate, the phased introduction of fungus gnat adults into the cages resulting in the presence in the substrate of prey of different instars and sizes and the addition of a high number of adult $D$. melanogaster as a food supplement for the adult predators. The high variation recorded in the number of fungus gnat larvae in the different substrates may be attributed to variation in the development of the fungus in the spawn, both in terms of quantity and its spatial distribution, which is the food source for the fungus gnats. Variations in temperature, relative humidity or soil humidity during the experiments are not probable causes, as variation in these factors was low and occurred for only short periods.

A moderate correlation was recorded between the number of predator progeny/ parental pair that subsequently emerged and the number of fungus gnat larvae in the substrate. According to Sensenbach et al. (2005) and Ugine et al. (2010), the survival and development of $C$. attenuata larvae are influenced by the relative abundance of the different instars of fungus gnat larvae in the rearing substrate, with the largest fungus gnat larvae being the most nutritious. Here, the different fungus gnat larval instars were not distinguished during our assessments of their abundance, but different instars were present in the substrate because adult fungus gnats were gradually introduced into the rearing cages and the first adults to emerge also laid eggs. Probably, a better correlation would have been recorded if only the numbers of $2^{\text {nd }}$ and $3^{\text {rd }}$ instar fungus gnat larvae were included in this analysis.

The method for rearing $C$. attenuata presented here is currently used by this research team. The additional information provided by these experiments confirms that when establishing new rearing units, it is best to use 10 pairs of flies per $25 \times 14 \times 3.5 \mathrm{~cm}$ cage, with at least some of the females about 20 days old (post-emergence). Parental pairs can be collected from the field or laboratory colonies as long as some field-collected adults are frequently added to the latter. We also conclude that the substrate used for rearing the predator should include some coconut fibre mixed with the soil.

When establishing new rearing cages, it is sometimes difficult to obtain enough males, whether laboratory reared or 
caught in the field, as males are less abundant than females (Lambert, 2006; Mateus, 2012). Future studies should determine the optimum ratio of males to females instead of using pairs. According to Morris \& Cloutier (1987), multiple copulations are recorded for both sexes of $C$. tigrina and a male is able to successfully fertilize six females. Another point that needs further study is the relative merits of using an $\mathrm{M}$ substrate obtained by mixing soil and coconut fibre after fungus gnats have been separately added to the soil and coconut fibre versus one in which the soil and coconut fibre are mixed together before the fungus gnats are added, which avoids any potential injury to the fungus gnat larvae during the mixing process. In this way, the rearing system for this predatory fly can be further improved.

ACKNOWLEDGEMENTS. This study was supported by national funds provided by the Fundação para a Ciência e Tecnologia (project PTDC/AGR-AAM/099723/2008). The authors are grateful to the growers J. Firmino and L. Canuto for allowing us access to their greenhouses to collect insects, P.M. Domingos (ITQB, Portugal) for supplying the D. melanogaster to start its mass rearing, J. Cadete (INIAV) for help with the rearing and $\mathrm{F}$. Menzel (Senckenberg Deutsches Entomologisches Institut, Germany) for the identification of fungus gnat. Special thanks are due to S. Kühne (Julius Kühn Institute, Germany) for his advice and explanations and D. Lupi (Università degli Studi di Milano, Italy). The authors would also like to thank anonymous reviewers for their valuable comments.

\section{REFERENCES}

Hennig W. 1964: Muscidae: Gattung Coenosia Meigen, section 63b. In Lindner E. (ed.): Die Fliegen der Palaearktischen Region. 7 (2) Erste Hälfte. Schweizerbart'sche Verlagsbuchhandlung, Stuttgart, pp. 518-619.

Gilioli G., Baumgärtner J. \& Vacante V. 2005: Temperature influences on functional response of Coenosia attenuata (Diptera: Muscidae) individuals. - J. Econ. Entomol. 98: 15241530.

KüHNE S. 1998: Open rearing of generalist predators: a strategy for improvement of biological pest control in greenhouses. Phytoparasitica 26: 277-281.

KüHne S. 2000: Räuberische Fliegen der Gattung Coenosia Meigen, 1826 (Diptera: Muscidae) und die Möglichkeit ihres Einsatzes bei der biologischen Schädlingsbekämpfung. - Studia Dipterol. (Suppl.) 9: 1-78.

Kühne S., Schrameyer K., Müller R. \& Menzel F. 1994: Räuberische Fliegen: ein bisher wenig beachteter Nützlingskomplex in Gewächshäusern. - Mitt. Biol. Bundesanst. Land. Forstw. 302: 1-75.

KüHNE S., Schiller K. \& DAhl U. 1997: Beitrag zur Lebensweise, Morphologie und Entwicklungsdauer der räuberischen Fliege Coenosia attenuata Stein (Diptera: Muscidae). - Gesunde Pfl. 49: 100-106.

LAMBert L. 2006: A good find! A fly that devours black flies. Sting 29: 8-14.
Martinez M. \& Cocquempot C. 2000: La mouche Coenosia attenuata nouvel auxiliaire prometteur en culture protégée. PHM - Rev. Hortic. 414: 50-52.

MarTins J.R.F. 2011: Coenosia attenuata Stein: Desenvolvimento de metodologias de criação e avaliação de taxas de predação sobre Diglyphus isaea (Walker). MSc. Thesis, Instituto Superior de Agronomia / UTL, Lisboa, 76 pp.

Martins J., Domingos C., Nunes R., Garcia A., Ramos C., Mateus C. \& Figueiredo E. 2012: Coenosia attenuata (Diptera: Muscidae), um predador em estudo para utilização em culturas protegidas - Rev. Ciênc. Agrár. 35: 229-235.

Mateus C. 2012: Bioecology and behaviour of Coenosia attenuata in greenhouse vegetable crops in the Oeste region, Portugal. - Bull. Insectol. 65: 257-263.

Mohrig W., Heller K., Hippa H., Vilkamaa P. \& Menzel F. 2012: Revision of the black fungus gnats (Diptera: Sciaridae) of North America. - Studia Dipterol. 19: 141-286.

Moreschi I. \& Colombo M. 1999: Una metodica per l'allavamento dei Ditteri predatori Coenosia attenuata e C. strigipes. - Informat. Fitopatol. 49: 61-64.

Moreschi I. \& Süss L. 1998: Osservazioni biologiche ed etologische su Coenosia attenuata Stein e Coenosia strigipes Stein (Diptera: Muscidae). — Boll. Zool. Agr. Bachicolt. 30: 185197.

Morris D.E. \& Cloutier C. 1987: Biology of the predatory fly Coenosia tigrina (Fab.) (Diptera: Anthomyiidae): reproduction, development, and larval feeding on earthworms in the laboratory. - Can. Entomol. 119: 381-393.

Pohl D., Kühne S., Karaca I. \& Moll E. 2011: Review of Coenosia attenuata Stein and its first record as a predator of important greenhouse pests in Turkey. - Phytoparasitica 40: 63-68.

Prieto R., Figueiredo E. \& Mexia A. 2005: Coenosia attenuata Stein (Diptera: Muscidae): prospecção e actividade em culturas protegidas em Portugal. - Bol. Sanid. Veget. Plagas 31: $39-45$.

Sensenbach E.J. 2004: Coenosia attenuata Stein (Diptera: Muscidae): A Predatory Fly in North American Greenhouses. MSc. Thesis, Cornell University, Ithaca, 83 pp.

Sensenbach E.J., Wraight S.P. \& Sanderson J.P. 2005: Biology and predatory feeding behavior of the hunter fly Coenosia attenuata. - IOBC WPRS Bull. 28: 229-232.

TÉllez M.M. \& TAPIA G. 2007: Compatibilidad Coenosia attenuata con diversas materias activas y otros enemigos naturales. In Martín-Trujillo M., Gázquez-Garrido J.C., Hoyos-Echevarria P. \& Muñoz-Odina P. (eds): XXXVII Seminario de Técnicos y Especialistas en Horticultura Almeria 2007. Ministerio de Medio Ambiente y Medio Rural y Marino, Madrid, pp. 931-938.

Ugine T.A., Sensenbach E.J., Sanderson J.P. \& Wraight S.P. 2010: Biology and feeding requirements of larval hunter flies Coenosia attenuata (Diptera: Muscidae) reared on larvae of the fungus gnat Bradysia impatiens (Diptera: Sciaridae). - J. Econ. Entomol. 103: 1149-1158.

VAlentini M. 2009: Nuove tecniche per l'allevamento massal di ditteri del genere Coenosia Meigen. $\mathrm{PhD}$. Thesis, Università di Bologna, Bologna, 68 pp.

Received August 8, 2014; revised and accepted March 20, 2015 Prepublished online May 15, 2015 